\title{
FRANS ANDRÍES, CERAMISTA DE AMBERES EN SEVILLA
}

\author{
POR CLAIRE DUMORTIER
}

Este artículo pretende desarrollar algo más ampliamente de lo que se ha hecho hasta el momento en la bibliografía española, la personalidad artística de Frans Andríes (llamado Francisco Andrea en los documentos sevillanos), un ceramista flamenco que se trasladó a Sevilla a mediados del siglo XVI. Se suministra aquí nueva información sobre su vida y obra en Amberes, casi desconocida en España y se sugieren algunas teorías acerca de su fecha de llegada a nuestro país. Otra nueva hipótesis de gran interés es la posible relación familiar entre Niculoso Francisco y otra famosa familia de ceramistas italianos establecidos en Amberes a principio del siglo: los "Frans".

This paper tends to develop, more widely than usual in the Spanish bibliography, the artistic personality of Frans Andries (called Francisco Andrea in Sevillian documents), a Flemish potmaker who moved to Seville in the middle of the sixteenth century. New information about his life and work in Antwerp, almost unknown in Spain, is given here and some ideas on his date of arrival in Spain are suggested. A new interpretation of the possible relationship between Niculoso Francisco and another famous family of Italian ceramists settled in Antwerp at the beginning of the century: the "Frans", could be another interesting new hypothesys to discuss.

Las relaciones artísticas y comerciales entre España y los Países Bajos meridionales conocieron una era de prosperidad bajo el reinado de Carlos $V^{1}$. Artesanos

1. Queremos hacer constar nuestra gratitud a Alfonso Pleguezuelo, profesor de Historia del Arte de la Universidad de Sevilla cuyos consejos nos resultaron muy valiosos a la hora de redactar este artículo que ha tenido la amabilidad de traducir al castellano y a Don Ramón Gutiérrez de la Peña por facilitamos la transcripción del documento incluido en el apéndice. Nuestro agradecimiento se extiende a todas las instituciones que nos han facilitado la investigación en Sevilla, especialmente al Comisariado General de las Relaciones Internacionales de la Comunidad Francesa de Bélgica y al Fondo de Investigación Fundamental y Colectiva, como iniciativa ministerial dentro del marco de los Museos Reales de Arte y de Historia de Bruselas. 
y artistas de regiones del Norte se instalaron en España o bien sus obras influyeron en la producción local ${ }^{2}$.

En el terreno de la cerámica, Sevilla era a fines de la Edad Media un centro de producción enraizado en la tradición hispano-musulmana. La instalación en la ciudad a fines del siglo XV de Niculoso Francisco, artista de origen italiano, renovó el arte, la técnica, el uso y la iconografía de la cerámica en este centro ${ }^{3}$. Este artista fabricó cerámicas de las llamadas "a la manera de Pisa" que algunos autores han interpretado como sinónimo de mayólicas. Se conservan varios paneles de azulejos firmados por Niculoso Francisco. También produjo figuras de terracota, como han demostrado los resultados de excavaciones efectuadas en el mismo solar de su taller en Triana ${ }^{4}$. Su producción, excepcional tanto por la calidad de las composiciones como por la precisión del dibujo, le convirtieron en abastecedor de los Reyes de Castilla, para los que hace en 1504 un gran retablo de la Visitación destinado al oratorio de los Reales Alcázares. A su fallecimiento, Niculoso Francisco deja dos hijos que continuaron el oficio. Se conocen piezas firmadas por Juan Bautista y datadas hacia 1530. En cuanto al segundo de los hijos, podría ser identificado con un "francisco Nycolaso" citado en 1533 en documentos de archivo ${ }^{5}$. La producción de mayólicas sevillanas parece interrumpirse en esa época. En efecto, los encargos conocidos como el realizado en 1526 a los Polido para el Palacio del Marqués de Tarifa (Casa de Pilatos) o el de los Reales Alcázares de Sevilla se refieren a azulejos de "arista" fabricados según la tradición mudéjar ${ }^{6}$.

Esta carencia de producción de mayólicas pudo tal vez motivar la llegada de artistas extranjeros en la segunda mitad del siglo XVI. Se sabe que en 1561, Frans Andríes, formado en Amberes, se encuentra en Sevilla ${ }^{7}$. Del mismo modo, Tomaso da Pesaro, que ha trabajado en Génova, también es citado allí en $1569^{8}$.

Esta breve contribución intenta, a la luz de documentos inéditos, conocer mejor y precisar el papel y la actividad de Frans Andríes en Amberes y en Sevilla.

2. Uno de los mejores ejemplos es el de Peter de Kempeneer conocido en España como Pedro de Campaña (1503-1579), nacido en Bruselas y residente en Sevilla de 1537 a 1563. Para este artista vease C. JUSTI: Peeter de Kempeneer genannt Maese Pedro Campaña en "Jahrbuch der preussischen Kunstsammlungen”, 5, 1884, p. 154-179; D. ANGULO: Pedro de Campaña Sevilla, 1951; N. DACOS: Pedro Campaña dopo Siviglia: arazzi e altri inediti en "Bolletino d'Arte", 8, 1980, p. 1-40; vease también J. M. SERRERA: Dibujos y tablas de los primeros años sevillanos de Pedro de Campaña, en "Archivo Español de Arte", 262, 1993, p. 279-286.

3. J. GESTOSO Y PÉREZ: Historia de los Barros Vidriados Sevillanos desde sus orígenes hasta nuestros días, Sevilla, 1904, p. 166-212.

4. A. PLEGUEZUELO: Francisco Niculoso Pisano: datos arqueológicos en "Faenza", LXXVIII, 1992, 3-4, p. 171-191, pl. XXXIV-XXXVIII.

5. Ibídem.

6. A. Wilson FROTHINGHAM: Tile Panels of Spain 1500-1650, New York, 1969, p. 77.

7. J. GESTOSO Y PÉREZ: ob. cit., p. 223-225.

8. Ibídem. 


\section{FRANS ANDRÍES, CERAMISTA EN AMBERES}

Frans Andríes nació en Amberes poco antes de $1535^{\circ}$. Era el segundo hijo de Anna van Dueren, también natural de esa ciudad, y de un ceramista de origen italiano llamado Guido Andríes. Este último puede ser considerado como el fabricante de mayólicas más importante de Amberes en el primer tercio del siglo XVI. En 1520 era dueño de un alfar llamado Den Salm (El Salmón), situado en la Kammenstraat (antes Cammerstraat). A su muerte, que acaeció antes de 1541, su viuda vuelve a casarse con Franchois Frans, también ceramista y perteneciente a una familia italiana que contaba con varios miembros instalados en Amberes. Este casamiento situó a Franchois Frans como jefe del citado alfar hasta la mayoría de edad de los hijos de Guido. Es muy probable que el joven Frans y sus cuatro hermanos aprendieran allí el oficio de ceramista. Durante este periodo, el taller $E l$ Salmón alcanzó su apogeo. Se sabe que de 1543 a 1561, entraron en él al menos cuatro aprendices y un empleado encargado de las cuentas de la fábrica ${ }^{10}$.

En 1550, un primer maestro ceramista, Hans Floris es, en efecto, citado como miembro de la "Gilde de Saint-Luc" (Cofradía de San Lucas) de Amberes. En 1552 la Cofradía inscribe una serie de nuevos miembros fabricantes de mayólica lo que parece apuntar hacia una regularización del oficio ${ }^{11}$. Entre ellos cabría destacar el nombre de Frans Andríes, de su hermano Joris y de su padrastro Franchois Frans. En 1556, Frans Andríes se va de Amberes. En ese momento otorga un poder notarial a Franchois Frans para que administre en su nombre los bienes recibidos en herencia al fallecimiento de su padre, principalmente las rentas de la casa donde tenía su sede El Salmón ${ }^{12}$. Sabemos que reside en Sevilla en 1561. Es, pues, lógico pensar que ya se había instalado en esta ciudad en 1556.

Varios factores jugaron probablemente un papel importante en la emigración de Frans Andríes hacia Sevilla. En primer lugar podríamos citar la presencia previa en España de Hans de Vriendt, más conocido por Hans Floris, pintor cerámico. Nacido en Amberes entre 1520 y 1524, perteneció a una célebre familia de artistas. Sus hermanos Cornelis, Frans y Jacob Floris fueron respectivamente arquitecto-escultor, pintor y pintor de vidrieras en Amberes ${ }^{13}$. Carl Van Mander alaba en 1604 la calidad de sus pinturas

9. C. DUMORTIER: Het atelier van de Antwerpse geleyerspotbacker Franchois Frans (I6de eeuw), en "Mededelingenblad Nederlandse Vereniging van Vrienden van de Ceramiek", 125, 1986, 5, p. 3-37.

10. Ibídem.

11. Ph. ROMBOUTS y Th. VAN LERIUS: De Liggeren en andere historische Archieven der Antwerpsche Sint-Lucasgilde. Les Liggeren et autres archives historiques de la Gilde anversoise de Saint-Luc, I, 1872, p. 182.

12. C. DUMORTIER: ob. cit., p. 4-37.

13. C. VAN DE VELDE: Frans Floris (1519/20-1570). Leven en werken. I. Tekst (Verhandelingen van de Koninklijke Academie voor Wetenschappen, Letteren en Schone Kunsten van Belgie. Klasse der Schone Kunsten), XXXVII, 30, 1975, p. 25. 
sobre cerámica ${ }^{14}$. Un documento de Amberes de 1551 comenta que Hans Floris reside en el extranjero ${ }^{15}$. Por cédula de 20 marzo de 1563, el rey Pelipe II le nombra su "maestro de azulejos", concediendole un salario desde el 24 de junio de $1562^{16}$. Quedaba encargado de decorar los sitios reales del Alcázar de Madrid y El Escorial, fijando su residencia en Talavera de la Reina (Toledo). Estuvo aún activo durante varios años y murió en $1567^{17}$. Ya que no hay indicios de su actividad en Amberes entre 1551 y 1561, podemos suponer que trabajaba ya en España por esa época. De ese modo, se podría sugerir que Hans Floris pudo tener contactos con los grandes centros españoles especializados en la fabricación de mayólicas y pudiera haber animado a su compatriota a emigrar a Sevilla.

Por otro lado, podríamos preguntarnos si existió algún lazo de parentesco entre la familia Frans instalada en Amberes y Niculoso Francisco. La ortografía del nombre de los miembros de la familia Frans evolucionó a lo largo de los años: leemos en 1513 que Jan Francisco de Bresse es fabricante de mayólica en Amberes ${ }^{18}$, más tarde su nombre adopta una forma más nórdica siendo citado como Jan Frans, igual que su hijo Jan Frans, su hermano Peter Frans y el sobrino de todos ellos Franchois Frans que dirigió el taller de Guido Andríes ${ }^{19}$. Es preciso puntualizar que Niculoso Francisco ${ }^{20}$ firma sus obras como "Niculoso" o como "Niculoso Francisco"; igualmente, su cita en los documentos aparece también como "Niculoso Francisco" 21. Estos datos permiten lanzar la hipótesis de que el apellido de este

14. C. VAN MANDER: Het Schielder-Boek, 1604, fol. 239 rto. "...Jan Floris zoo'n bekwaam en vermaard bakker van geglazuurde potten, dat hij in de Nederlanden door niemand geëvenaard en om wille van zijn begaafdheid naar Spanje ontboden werd in dienst van koning Philips, waar hij jong gestorven is. $\mathrm{Hij}$ was een man met beeldende fantasie en teekende en schilderde op dat aardewerk of porselein allerlei sierlijke historietjes en figuurtjes, waarvan Frans er een aantal in huis had, die het bezien zeer waard waren." Texto transcrito de Het Schilder-boek van Carel van Mander. Het leven der luchtige Nederlandsche en Hoogduitsche schilders, Cuarta edición, Amsterdam-Amberes, 1950, p. 109.

15. C. VAN DE VELDE: $o b$. cit., p. 439.

16. J. A. CEÁN BERMÚDEZ: Diccionario histórico de los más ilustres profesores en España (La Real Academia de Bellas Artes de San Fernando), t. II, Madrid, 1800, pp. 128-129.

17. V. GERARD: De Castillo a Palacio. El Alcázar de Madrid en el siglo XVI, Bilbao, 1984, p. 10; A. RAY: Sixteenth-century pottery in Castile: a documentary study, en "The Burlington Magazine", CXXXIII, 1058, 1991, p. 298-305.

18. H. NICAISE: Notes sur les faïenciers italiens établis à Anvers dans le premier tiers du XVIe siècle, en "Revue Belge de Philologie et d'Histoire", XVI, 1937, p. 194-196; C. DUMORTIER: Les faïenciers italiens à Anvers au XVIe siècle. Aspects historiques, en "Faenza", LXXIII, 1987, 4-6, p. 161-172.

19. Ibídem.

20. Los autores citan casi siempre a este artista como "Francisco Niculoso". Vease J. GESTOSO: ob. cit.; p. 166-182; A. RAY: Francisco Niculoso called Pisano en "Italian Renaissance Pottery", Papers written in association with a colloquium at the British Museum (ed. by T. Wilson), Londres, 1991, p. 261-266.

21. Sobre el panel que reviste la sepultura de Iñigo López, conservado en la iglesia de Santa Ana de Triana y datado en 1503, aparece la inscripción "NICULOSO FRANCISCO ITALIANO ME FECIT..."; la misma firma aparece sobre los azulejos de la portada de la iglesia en el Monasterio de Santa Paula de Sevilla, donde figura también la fecha 1504, igual que sobre el retablo de la Visitación, conservado en la capilla de los 
ceramista era Francisco y de que el nombre - que prevalecía siempre sobre el apellido en aquella época - era Niculosus. Por otro lado, su hijo firma también sus obras como "Juan Bautista Pisano" 22 . Tales datos conducen a la idea de que estos ceramistas sevillanos pertenecían a una familia con el patronímico Francisco como apellido. El ceramista Niculoso Francisco tuvo al menos dos hijos, el citado antes como Juan Bautista, nacido en 1508, y Francisco, nacido en 1511. Por otro lado, en Amberes había igualmente otra familia con el apellido Francisco que contaba con tres hermanos de los que dos son citados en los documentos de esa ciudad: Peter, que era mercader, y Jan, ceramista, que tuvo un hijo al que dio su mismo nombre. El tercer hermano, Franciscus, tuvo dos hijos, Franchois y Jan Baptista. La coincidencia entre estos dos últimos nombres y los de los hijos de Niculoso es, cuanto menos, curiosa. Los documentos de Amberes permiten conocer aproximadamente la edad de Franchois Frans mientras que la de Juan Bautista es aún desconocida. En dos documentos de 1571, Franchois Frans es citado como persona de 50 a 52 años de edad lo que significaría que habría nacido hacia 1518-1520 aunque esta mención no es del todo fiable ${ }^{23}$. En esa época se percibe una cierta imprecisión en las declaraciones de edad de los individuos, declaraciones que se modifican en función de factores exteriores. Estos datos quedan hoy como elementos de reflexión que hacen hipotética la existencia de lazos familiares entre los ceramistas de Amberes y los de Sevilla que habrían podido favorecer la emigración de Frans Andríes a la ciudad del Guadalquivir.

La introducción en Amberes de sistemas de revestimiento de origen español atestigua otro posible lazo entre las dos regiones. Es en Sevilla donde Niculoso Francisco ha realizado los primeros paneles de azulejos historiados. En Amberes, en su taller de la Kammenstraat, Guido Andríes fabricó hacia 1530 azulejos para pavimento, según la tradición italiana. Pero, por otra parte, su producción también abarcaba paneles de azulejos destinados a decorar los muros en una tradición más propia de raíces mudéjares. El ejemplo más antiguo de panel historiado que conocemos es un conjunto de varios azulejos pertenecientes a dos pequeños paneles de los que uno representa la Crucifixión, rodeado de una guirnalda de follajes, frutos y vasos estilizados. Del otro panel no hemos conservado más que fragmentos del marco. Podrían ser datados hacia $1532^{24}$. Otro panel cerámico hecho en Amberes

Alcázares Reales. Sobre el retablo del Monasterio de Tentudía, ejecutado en 1518, leemos "NICVLOSUS PISANVS ME FECIT..." y en el retablo de la iglesia parroquial de Flores de Avila datado en 1526, "NICVLOSVS ME FECIT". En los documentos se vuelve a leer el nombre de Niculoso Francisco, por ejemplo en 1529, cuando es citada Elena del Villar como "mujer de Niculoso Francisco difunto".

22. A. J. MORALES: Francisco Niculoso Pisano, Col. Arte Hispalense n 14. Excma. Dip. Prov. de Sevilla, Barcelona, 1977.

23. C. DUMORTIER: Het atelier van de Antwerpse geleyerspotbacker..., p. 4.

24. Estos azulejos han sido hallados durante las excavaciones del antiguo asilo de la Abadía de Hemiksen en Amberes. Azulejos de pavimento del mismo formato han sido encontrados en el mismo lugar. Algunos de ellos han recibido idéntica decoración que los que revisten la antigua abadía de 
muestra la fecha de $1544^{25}$ y sobre el panel de la Conversión de San Pablo conservado en el Museo Vleeshuis de Amberes figura el año $1547^{26}$. En Rouen, hacia 1550, Masseot Abaquesne ejecutó también paneles de azulejos ${ }^{27}$. Estos conjuntos se cuentan entre los primeros paneles de azulejos historiados realizados en las regiones del Norte después de las producciones sevillanas. Esta producción no ha sido directamente influenciada por la mayólica italiana ya que los centros de producción de ese país no estaban especializados en este tipo de obras.

\section{FRANCISCO ANDREA, CERAMISTA EN SEVILLA}

Tres documentos de archivo aclaran la actividad de Frans Andríes (castellanizado como Francisco Andrea) en Sevilla. Un contrato del 19 de junio de 1561, publicado por Gestoso y Pérez, cita a Roque Hernández, ollero, y a Francisco Andrea, flamenco vecino de Triana ${ }^{28}$. Formaron compañía para producir loza y azulejos (el hazer del azulejo de piza y en el fazer de loça de piza). Las condiciones de esta colaboración mencionan claramente la actividad de Frans Andríes. Durante un año y medio vivirá en casa de Roque Hernández y se dedicará a enseñarle la pintura de azulejos y de lozas. Para decorar esas cerámicas utilizará los colores de Pisa. Por su parte, Roque Hernández, pondría el barro y el combustible necesario para la fabricación y cocción de las cerámicas que serán pintadas por Francisco Andrea. Las piezas terminadas serían vendidas en el propio taller y el beneficio de la venta sería compartido por ambos socios.

De los términos del contrato se desprende que Francisco Andrea era especialista en pintar loça de Pisa, es decir, vajillas a la manera de Pisa, no azulejos de tipo mudéjar como los de "arista" o los de "cuerda seca". Como otros autores han reconocido habitualmente, este texto deja de relieve la novedad que trae de Francisco Andrea con la técnica de la mayólica, lo que implica aceptar la previa desaparición de esta especialidad cerámica en Sevilla durante varios años. Por otro lado Francisco Andrea se obliga a

Herkenrode (cerca de Hasselt, Bélgica), encargados en 1532. La comparación entre los dos conjuntos induce a datarlos en la misma época. Vease C: DUMORTIER y T. OOST: Antwerpse majolicategels uit het voormalig refugiehuis van de abdij van Hemiksen, en "Blik in de bodem. recent stadsarcheologisch onderzoek in Antwerpen" (redactado por J. VEECKMAN), Anvers, 1992, p. 23-29.

25. Inv. 22. A 14. Antigua colección Frans Claes; M. LAURENT: Guido di Savino and the Earthenware of Antwerp, en "The Burlington magazine", XLI, 1922, p. 294.

26. Ibídem; Ch. VAN HERCK, Antwerpsch Plateel. De Saulus'Bekering van 1547 en enkele aanverwante fragmenten, en “Jaarkoek vn Antwerpens's Oud heid kundige Kring, XII, 1936, p. 62-66; J. DOULLEZ, De Bekering Saulus. Aanvullende gegevens over een befaamd tegeltableau in het Vleeshuis, "Antwerpen. Tijdschrift der Stad Antwerpen", III, 1957, p. 45-47. Vease también C. DUMORTIER: Het atelier van de Antwerpse geleyerspotbacker..., p. 4-37 y la bibliografía citada en este último trabajo.

27. C. VAUDOUR: Masseot Abaquesne, faïencier a Rouen, en "L'Estampille", 130, 1981, p. 20-32; ÍDEM: Masseot Abaquesne. La cerámica de Rouen al segle XVI, en "Butletí Informatiu de Ceramica", 25,1985 , p. $24-29 ; 26,1985$, p. $42-46$ y la bibliografía citada en estos dos últimos trabajos.

28. Archivo Histórico Provincial de Sevilla. Archivo General de Protocolos, leg. 2.319, fol. 960 rto-961 vto. Publicado por J. GESTOSO Y PEREZ: ob. cit., p. 223-225. 
pagar los componentes necesarios para elaborar esta pintura sobre cerámica. De este modo, podemos también suponer que él mismo haría el encargo de abastecimiento de tales materiales y su recepción. Su experiencia en el taller familiar en Amberes le permitiría, sin duda, conocer directamente las fuentes de aprovisionamiento.

Un acta de archivo en Amberes, datada el 28 de agosto de 1563, puede ser puesta en relación con la actividad de Francisco Andrea en el taller de Roque Hernández en Sevilla. En ella se consigna que Frans Andríes debe a su hermano Joris doscientos florines por el envío de ciertas mercaderías a Coenraet van Overvelt que vive en Sevilla ${ }^{29}$. Podemos imaginar que este contrato se refiere al envío de los componentes utilizados para la fabricación de mayólicas: óxidos metálicos costosos como el cobalto importado de Oriente o del estaño, procedente de Inglaterra o también de álcali ${ }^{30}$.

Cuando acaba el plazo de asociación entre Roque Hernández y Frans Andríes, el 19 de diciembre de 1562, éste último debió buscar otra colaboración. Un documento de fecha 7 de enero de 1565, revela que Jorge Enríquez y Francisco Andrea, ceramistas, tenían una deuda con Martín Díaz, también ceramista, por valor de 14 ducados de oro como pago de la renta por el alquiler de un alfar (unas casas ollerías) donde han estado viviendo (Documento $\mathrm{n}^{\circ} 1$ ). La firma de Francisco Andrea, aunque abreviada, es idéntica a la del documento de 1561. Por el contrario, la personalidad de Jorge Enríquez no es conocida. En su relación de olleros, J. Gestoso menciona varios con este apellido (hay un Diego, un Juan y un Pedro) pero ninguno lleva Jorge por nombre. Por el contrario, el nombre de Martín Díaz al que los dos ceramistas han alquilado el alfar aparece citado en varias ocasiones. En 1553 Martín Díaz alquila en Triana unas casas ollerías. En 1564, intenta recuperar una deuda ${ }^{31}$. Los términos del documento de 1565 confirman que Francisco Andrea no poseía alfar propio sino que acostumbraba a asociarse a otro ceramista ya instalado. De esta última colaboración podemos deducir que él se reservaba el trabajo de pintura sobre cerámica.

En un estudio que J. M. dos Santos Simôes hizo en 1959, este autor hace una contribución al conocimiento de la producción de Roque Hernández y de Francisco Andrea $^{32}$. En él se refiere a un panel de azulejos colocado como frontal de altar que representa una Adoración de los Magos, conservado en la Catedral de Córdoba. Esta pintura muestra el monograma "Ro Es". El autor interpreta estas iniciales asociandolas a la obra de Roque Hernández al que Francisco Andrea había enseñado la pintura cerámica. Apoyándose en análisis comparativos y considerando que Francisco Andrea era el reimplantador de la técnica de la pintura cerámica, Santos Simôes atribuyó a este último otro frontal de altar de azulejos con la escena de la Caída del

29. Archivo Municipal de Amberes (Stadsarchief Antwerpen), Registro de Concejalías (Schepenregister) 295: 1563 (H. M. II), fol. 134 vto-135 rto.

30. Cipriano Piccolpasso llama a este producto "cenere di Levante". Según B. LEACH: Le livre du potier (edición al cuidado de M. SCALBERT-BELLAIGUE et B. LHOTE-SULMONT): "término genérico para los compuestos de sodio y de potasio designando a veces cal o magnesio. Se usan para permitir la vitrificación de tiestos y bamices y se obtiene a partir de sales, silicatos, espatos y cenizas vegetales".

31. J. GESTOSO Y PÉREZ: ob. cit., p. 400.

32. J. M. DOS SANTOS SIMÔES: Frontales de altar de azulejo en la Mezquita-Catedral de Córdoba, en "Archivo Español de Arte", 32, 1959, p. 39-57. 
Maná, ejecutado también para la Mezquita-Catedral de Córdoba. Este panel figura concretamente en la Capilla de Pedro Fernández de Valenzuela, cerrada por una monumental reja adornada con las armas del donante, grutescos y la fecha 1554. El panel de cerámica fue realizado en 1558 , como lo atestigua una inscripción pintada sobre un marco cerámico que rodea la escena bíblica. Sobre el altar se levanta un retablo de pinturas atribuido a Pedro de Campaña (Peter de Kempeneer). El estilo del panel cerámico, caracterizado por un tratamiento muy minucioso de los motivos como el vaso llevado por un putto, los bucles rubios de un joven o las actitudes de las mujeres hacen pensar en el Manierismo de las regiones del Norte, próximas a la Escuela de Fontainebleau. Como ya señaló Santos Simôes, ninguna obra cerámica sevillana de mediados del siglo XVI ofrece una calidad semejante en la representación. Otros dos paneles de azulejos conservados en la Quinta de Bacalhoa en Portugal son igualmente vinculados a la obra de Francisco Andrea. Uno representa Susana y los Viejos, el otro, El Rapto de las Sabinas cuya fuente de inspiración es un grabado de Enea Vico ${ }^{33}$. El primer panel de azulejos lleva la fecha 1565. La actividad documentada de Francisco Andrea en Sevilla en 1565 no contradice, en principio, la atribución de tales paneles a este ceramista.

En conclusión, estos nuevos datos biográficos hacen conocer mejor la actividad de Frans Andríes en Sevilla. Maestro de la Cofradía de San Lucas en Amberes en 1552, se traslada hacia 1556 a la Península Ibérica. En Sevilla al menos hasta 1565 , trabajó esencialmente como pintor cerámico como atestigua la asociación establecida con ceramistas sevillanos. Allí transmite el método para pintar sobre cerámica a Roque Hernández y, en consecuencia, se constituye en el origen de la "escuela" sevillana. Recordemos que éste último probablemente haría más tarde lo mismo con su yerno Cristóbal de Augusta quien, en 1575 ejecuta el célebre encargo de azulejos para los zócalos del Salón de Carlos V en el Alcázar sevillano ${ }^{34}$.

33. J. M. DOS SANTOS SIMÔES: Azulejaria em Portugal nos Séculos XV e XVI. Introduçao Geral (Fundaçâo Calouste Gulbenkian), Lisboa, 1969 ( $2^{a}$ ed. Lisboa, 1990, p. 104-105). Para la representación de Susana y los Viejos vease C. DUMORTIER: Des carrreaux en majolique anversoise conservés aux Musées royaux d'Art et d'Histoire, en "Bulletin des Musées royaux d'Art et d'Histoire", 62, 1991, p. 221-224.

34. J. GESTOSO Y PÉREZ: ob. cit., p. 417-418. 


\title{
APÉNDICE DOCUMENTAL
}

\section{DOCUMENTO 1}

Archivo Histórico Provincial de Sevilla. Archivo General de Protocolos, Leg. 2324.

Fol. $139 \mathrm{v}-140 \mathrm{r}$

Año: 1565,17 enero.

\author{
Jorge Enríquez y Francisco Andrea declaran debera a martín Díaz 14 ducados de \\ oro por el alquiler de una casaollería .
}

\begin{abstract}
"Sepan quantos esta carta vieren cómo yo Jorge Enríquez/ e yo Francisco Andrea, olleros, vezinos desta ciudad/ de Sevilla en Triana ambos a dos juntamente/ e de mancomund e aboz de uno y cada uno de nos por el/todo renunciado al abtentica hoc y ta de duobus reis/ devendi y el abtentica presente de si/ de jusoribus y el beneficio de la división y excursión e to/ das las demás leyes que hablan en raçón de la / mancomunidad, otorgamos e conocemos que de/vemos e nos obligamos de dar e pagar a vos/Martín Díaz, ollero, vezino de la dicha Triana que estades/ presente a qvien vuestro poder ouiere catorze/ ducados de oro los quales so de resto de la / renta que nos obligamos de vos pagar de vnas casas/ollerías (en que biuiamos) que de vos theníamos arrendadas e renunciamos/ que no podamos dezir ni alegar que lo suso dicho no es ni pasa/ ansí e si lo dixeremos o alegaremos qve no nos vala/ los quales dichos catorze ducados deste dicho debdo prome/temos e nos obligamos de vos dos dar y pagar aquí/ en Sevilla sin pleito alguno los ocho ducados dellos/ de oy día qvesta carta es fecha e otorgada en un mes/ cumplido primero siguiente e los seis ducados restantes de oy día/ que esta carta es fecha en un mes y medio primero siguiente so pena del/ doblo de cada paga para cuyo cumplimiento e paga/ por esta carta, damos e otorgamos todo nuestro poder/ cumplido a qvales qvier juezes y justicias desta çiudad de Sevilla e de otras partes para que sin/ ser llamados ni reqveridos ni oidos ni vençidos/sobre esta raçon nos puedan prender y fazer execución/ en nos y en cada vno de nos y en todos nuestros bienes/ e los vendan e los rematen porqve de los maravedies/ que valieren y montaren vos entreguen y fagan/ pago deste dicho deudo a los dichos plaços e de las/ que se vos recreçieren como si fuese pagado/ en cosa juzgada e por nos consentida, sobre lo qval/ renunciamos quales qvier leyes que en nuestro fabor sean/ y especial renunciamos la ley e derechos en qve diz que general renunciación/ de leyes fecha, non vala e para lo ansí pagar y cum/plir e auer por firme obligamos nuestras personas/ e bienes avidos e por auer.

Fecha la carta en Seuilla/ estando en el oficio de mí Juan Pérez escriuano público/ de Sevilla, jueves diez y siete días del mes de/ henero de mill e qvinientos e sesenta e çinco años $y /$ los dichos otorgantes lo firmaron de sus nombres/e presentaron por testigos de su conocimiento a/ dos hombres que se nombraron el vno Juan Enrríqvez/ e Francisco de Sigura los
\end{abstract}


qvales estando presentes di/xeron que los conocen e saben que son los propios otorgantes/ desta escriptura y se llaman como se han nonbrado y ansí/ lo juraron en forma, siendo testigos Jullian de Escobar y Lope/ de Salzedo vezinos de Sevilla. Va tachado de duobus, no vala/ y entre renglones, en que bivíamos, vala. "

Francisco Andrea (rúbrica)

Jorge Enrriqvez (rúbrica)

Iohan Pérez, escriuano de Sevilla (rúbrica)

Lope de Salzedo, escriuano de Sevilla (rúbrica)

Jullian de Escobar, escriuano de Seuilla (rúbrica) 